\title{
Participatory Designs and Epistemic Authority in Knowledge Platforms for Sustainability
}

\author{
Alejandro Esguerra and Sandra van der $\mathrm{Hel}^{1,2}$ \\ Please note that this is the post acceptance version. The article will appear in Global \\ Environmental Politics 21 (1) 2021.
}

\begin{abstract}
Expert organizations in sustainability governance increasingly adopt participatory strategies to strengthen their knowledge claims. We introduce the notion of knowledge platforms for sustainability to conceptualize expert organizations that not only rhetorically embrace but also actively attempt to institutionalize the norm of stakeholder participation. In seeking authority in sustainability governance, knowledge platforms for sustainability encounter a tension between the ambition of stakeholder participation and principles of scientific autonomy and consensus that have long been perceived as foundational to the epistemic authority of expert organizations. Taking this tension as a starting point, we utilize a dynamic perspective on epistemic authority to investigate the contestations over institutional designs. We compare the institutionalization of participatory designs over time in two knowledge platforms for sustainability - the Intergovernmental Platform for Biodiversity and Ecosystem Services (IPBES) and Future Earth. Our comparison reveals that institutional designs for participation open up the process of knowledge creation and evaluation and allow for the inclusion of a broader knowledge base and set of experiences. Yet, in seeking epistemic authority, knowledge platforms also reinforce existing power structures by redrawing boundaries that protect scientific autonomy and privilege relationships with elite actors. We conclude that the institutionalization of participation is shaped by the way in which knowledge platforms seek epistemic authority (specifically from whom), which in turn shapes whose and which knowledge is presented as legitimate in global environmental politics.
\end{abstract}

\section{Introduction}

Global environmental politics deals with highly complex issues, which makes knowledge an integral part of environmental governance (Dooley and Gupta 2017; Lidskog and Sundqvist 2015; Littoz-Monnet 2017). States, firms and international organizations follow the advice of expert organizations because of their epistemic authority - their authoritative claim to relevant knowledge (Haas 2017). In the ozone regime, for example, like-minded experts successfully

\footnotetext{
${ }^{1}$ Previous versions of this paper were presented at the 59th Annual Convention of the International Studies Association (ISA) in San Francisco as well as the Myxa Research Group, Berlin. The input of all participants in these meetings is gratefully acknowledged. We would also like to thank Frank Biermann and three anonymous reviewers for their excellent comments.

${ }^{2}$ The authors contributed equally to this article.
} 
supported policy-makers in the development of the Montreal Protocol (Haas 1992). In the climate regime, the Intergovernmental Panel for Climate Change (IPCC) provides scientific evidence, for instance, on the threats of sea level rise (Beck and Mahony 2018). Yet, expert organizations are increasingly criticized for failing to deal effectively with the urgent, complex and contested challenges of global change (Haas and Stevens 2011) and for neglecting to include knowledge sources from outside of elite science (Stirling, 2008). In response, scholars and practitioners alike call for "opening up" (Stirling 2008) expert organizations by expanding participation in order to enhance the relevance of expertise for addressing environmental problems and supporting sustainability transformations (De Pryck and Wanneau 2017; Garard and Kowarsch 2017; Opgenoorth et al 2014; Turnhout et al 2012).

In this paper, we present an empirical comparison of two new expert organizations that claim to innovate expertise by adopting the imperative of participation - the Intergovernmental Platform for Biodiversity and Ecosystem Services (IPBES) and the research platform Future Earth: Research for Global Sustainability. Founded in 2012, IPBES is an intergovernmental organization that aims to provide policymakers with state-of-the-art knowledge regarding biodiversity, as well as tools and methods to protect and sustainably use natural assets. In contrast, Future Earth, founded also in 2012, is a research organization that strives to integrate and coordinate solutions-oriented science for sustainability. These organizations differ in their foundations as assessment versus knowledge-generating institutions, yet they share an explicit commitment to participation at the global level. As such, they form two contrasting institutionalizations of the "participatory turn" (Bäckstrand 2003) in global knowledge production. To conceptualize this development, we introduce the notion of knowledge platforms for sustainability as a new type of expert organization that not only rhetorically embraces, but also attempts to institutionalize the norm of stakeholder participation.

Institutionalizing stakeholder participation requires innovation in the institutional design of expert organizations. The design of expert organizations has long been guided by principles of consensus, autonomy and policy relevance without being prescriptive (Beck and Mahony 2018; Haas 2017; Keller 2010). These principles are challenged by the inclusion of new actors and multiple perspectives in environmental knowledge making. Thus, while stakeholder participation in knowledge platforms for sustainability promises to increase the legitimacy of global environmental knowledge, it also challenges the conventional foundations of epistemic authority. This apparent tension inspired us to examine empirically how epistemic authority is constructed and maintained (Beck et al 2017; Kunseler and Tuinstra 2017). Therefore, we ask how and with what effects knowledge platforms for sustainability strive for epistemic authority?

More specifically, we consider three dimensions of the relationship between epistemic authority, participation and the design of knowledge platforms for sustainability. First, we consider how seeking epistemic authority shapes the institutional design of knowledge platforms. Here, we pay attention to the various participatory designs proposed and the negotiations over eventual design choices. Second, we consider how design choices in knowledge platforms, in turn, shape how participation is enacted, i.e. who can participate in knowledge platforms and in what way. Third, we ask how institutional designs for participation affect epistemic authority. That is, we consider both whose and which knowledge comes to be considered true and relevant for sustainability, and which actors are likely to accept these knowledge claims. In other words, we investigate how epistemic authority is both a driver and an outcome of the way participation is institutionalized in knowledge platforms for sustainability. 


\section{(Figure One)}

Figure 1.1. Three dimensions of the relationship between epistemic authority, participation and the design of knowledge platforms for sustainability: (1) Seeking epistemic authority affects institutional design; (2) Institutional design affects who can participate in knowledge platforms for sustainability and in what way; (3) Participation affects whose and which knowledge comes to be considered true and relevant for sustainability, and which actors are likely to accept these knowledge claims.

The next section introduces the notion of knowledge platforms for sustainability. Subsequently, we argue for a dynamic perspective on authority based on three literatures in International Relations (IR) and Science and Technology Studies (STS) and operationalize an institutional design perspective that focuses on epistemic authority in the making. The empirical section presents two cases of knowledge platforms for sustainability - IPBES and Future Earth - and highlights ongoing negotiations and contestations over different elements of these platforms' institutional designs. We discuss these findings in the conclusion and outline the implications for global environmental politics.

\section{Knowledge Platforms for Sustainability}

With the "participatory turn" in knowledge making, a specific type of expert organization has emerged, which we call knowledge platforms for sustainability. They adopt the principle of participation at the global level (Esguerra et al 2017; van der Hel 2016). They differ from other expert organizations in their ambition to advance a participatory format which includes a broad array of experts and stakeholders. They assess state-of-the-art knowledge as well as catalyze efforts to generate new knowledge for sustainability and provide this knowledge to various audiences in order to guide societal transformation (Garard and Kowarsch 2017; De Pryck and Wanneau 2017; Beck and Forsyth 2019). Their platform character aims at facilitating connections between knowledge holders and decision-makers, including both public and private actors (Gustafson and Lidskog 2018).

These new tasks and roles create tensions between conventional forms of epistemic authority and novel forms of legitimizing that authority through the participation and inclusion of different knowledge systems (Haas 2017). First, the imperative of participation questions the exclusive relationship between states and expert organizations. This relationship, which forms the basis of "politically delegated epistemic authority," is, for example, foundational to the IPCC, which is commissioned by governments to provide an authoritative assessment of the state of climate knowledge (Zürn et al 2012, 91). With the opening up to non-state actors as both intended audience and participants in knowledge production and assessment, knowledge platforms for sustainability challenge this privileged relationship between science and state. Second, knowledge platforms challenge the exclusive access of scientists to preside over the pursuit and interpretation of scientific findings. For example, the IPCC is considered successful in speaking "on behalf of global science with one voice, thereby acquiring a reputation as the epistemic authority in matters of climate policy" (Beck et al 2014, 80). The effort to open up involves expanding the number of contributors, rethinking what forms of knowledge are legitimate, and thus, calling into question the exclusive position of science as well as the principle of consensus. Together, this dual challenge creates a need for knowledge platforms for sustainability to rethink the relationship between science and politics. 


\section{Epistemic authority in global environmental politics}

Our aim is to explain how and with what effect knowledge platforms for sustainability strive for epistemic authority. We define epistemic authority as the authoritative interpretation of relevant knowledge for governance. In this definition we use the term knowledge instead of science to indicate that we are interested in the multiple forms of knowledge that are potentially mobilized by knowledge platforms for sustainability. Moreover, we use the term governance instead of policy-making to indicate that we focus on multiple actors, including policy-makers as well as other public and private actors that make up potential 'audiences' of knowledge platforms for sustainability (similar to e.g. Beck et al 2017).

Different analytical traditions have developed concepts on epistemic authority. First, in global environmental politics scholars have drawn from the foundational work of Peter Haas (1992) on epistemic communities. Epistemic communities - networks of scientific experts within a specific policy area - may change states' interests because of their authoritative claim to consensual, policy-relevant knowledge. For Haas, expert organizations "rely on willing deference by their audiences" given the "absence of conventional material capabilities for inducing (...) others to adhere to their analysis" (Haas, 2017, 221). Their epistemic authority ultimately rests on the legitimacy of scientific communities and assessments as perceived by states, international organizations, and private actors. That is, when expert organizations are regarded as legitimate, they carry authority. This perspective largely aligns with the literature on Global Environmental Assessments (GEAs) that puts forward salience, credibility and legitimacy as three important conditions for effectiveness (Cash et al 2003; Mitchell et al 2006). Thus, this perspective advances an understanding of epistemic authority based on a set of principles that expert organizations can or should achieve. Epistemic authority, in other words, is the causal variable that explains why states or firms defer to scientific claims and may ultimately change their behavior.

Second, a different take on epistemic authority comes from STS. Whereas the approaches above understand epistemic authority as the explanans (that which explains), the STS perspective, in contrast, focuses on the construction of epistemic authority itself so that authority turns into the explanandum (that which should be explained) (see Hajer and Pelzer 2018, 223). This approach examines epistemic authority as 'in the making', which is to ask how the authoritative claim to relevant knowledge for governance comes about. Rather than thinking of epistemic authority as built on a specific set of principles, attention is placed on the practices through which authority is acquired, protected, challenged and expanded. An STS perspective on epistemic authority raises questions about, "who belongs within the relevant expert collective, and hence is entitled to speak for it, as well as who does not belong" (Beck et al. 2017, 1068). Conflicts over epistemic authority are mainly about who has the right to speak for science and that right is potentially challenged by the participatory turn in scientific knowledge production. As Sheila Jasanoff has argued, "[t]horoughgoing changes in the production of science cannot but affect the foundations of scientific authority" (Jasanoff $2005,213)$. From this perspective, it thus becomes relevant to ask how participation in scientific knowledge production affects the making of epistemic authority.

Third, conceptualizing epistemic authority as 'in the making' resonates with recent advances in IR on authority in global governance (Krisch 2017; Sending 2017). This scholarship recognizes that authority "is often contested and has to be regained in competition and cooperation" (Krisch 2017, 245). Ole Jacob Sending in particular has challenged IR scholarship for not providing analytical tools to explain how consensus emerged within an epistemic community, "and how this particular group prevailed over others to become recognized as an authority" (Sending 2015,4). According to Sending, epistemic communities, 
international organizations and, in extension, knowledge platforms compete with other actors for recognition as authorities in the interpretation of relevant knowledge (Sending 2015).

In this paper, we suggest that all three analytical traditions agree that epistemic authority is about the authoritative interpretation of relevant knowledge for governance, including its exclusive and selective effects (Haas 2017; Beck et al 2017). We expand Haas' work by examining epistemic authority in the making. The integration of STS and recent IR approaches allows us to inquire how epistemic authority is made, contested and reinvented (Allan 2017; Lidskog and Sundqvist 2015). In particular, we are interested in how, in response to changes in the conditions and demands made of global environmental politics, knowledge platforms strive for epistemic authority (Sending 2017). They do so by interacting with people and groups inside and outside of the expert community (Lidskog and Sundqvist 2018) and by negotiating the institutional designs that shape the making of environmental knowledge (Beck et al. 2017; Montana 2019).

\section{Studying institutional designs of participation in knowledge platforms for sustainability}

We operationalize this dynamic perspective on epistemic authority by investigating how actors negotiate the institutional designs of knowledge platforms for sustainability as a means to strive for recognition. Scholars in STS have been particularly vocal in stressing that "expertise does not simply lie in specific exercises of knowledge-making" but also in "the institutional dynamics in which knowledge is rendered authoritative" (Beck et al. 2017, 1069). Institutional designs define the power relations between participants and bring about specific knowledge products (Montana 2019). From this perspective, we regard design choices as the locus where the dynamic and contested nature of epistemic authority becomes visible (Miller and Wyborn 2019).

Studying the ways in which knowledge platforms for sustainability reconfigure epistemic authority, we compare the participatory design choices of IPBES and Future Earth. We inquire how and why IPBES and Future Earth struggle and differ in their attempts to institutionalize participation. More specifically, we first consider (a) why in each organization actors have suggested institutionalizing principles of participation. Then, we investigate how the imperative of participation becomes institutionalized as part of (b) the organizational structures as well as (c) the conceptual frameworks of each case. Both items are key components of the negotiated institutional designs that seek to establish the authoritative knowledge of a phenomenon such as sustainability. Finally, we examine (d) the participation strategy that determines who participates and with what rights. With this operationalization of the why, how, and who, we investigate the struggles over how the making of knowledge is organized in seeking epistemic authority in global governance.

We used rich empirical material to build a comparison of both cases in three stages. First, we conducted document analysis of the IISD reporting service (IPBES), negotiation documents (IPBES and Future Earth) and vision and design documents (IPBES and Future Earth) from 2012 to 2018 . Then, we built our analysis on our experience as participant observers at IPBES Plenary Sessions in 2013 and 2015 as well as meetings of Future Earth in 2012 and 2016. Finally, we analyzed opinion pieces in scientific journals that lobby for distinct designs and refer to the relevant academic literature. Using these many types of materials allowed for a rich understanding of the various proposals for institutional designs, the justifications for design choices, and the negotiations through which the eventual organizational structures, conceptual frameworks and participation strategies of the platforms materialized. 


\section{Institutional designs of participation in IPBES \& Future Earth}

\section{Participatory ambitions of IPBES and Future Earth}

Seeking to position themselves as relevant knowledge actors in the domain of sustainable development, both IPBES and Future Earth present themselves as participatory platforms that contribute to solutions for sustainability challenges. In supporting these ambitions, both platforms seek to innovate the institutional design of expert organizations. The resulting design choices are the products of extensive negotiations with many design options on the table.

For IPBES, a gap analysis in the early negotiation phase indicated "the need to include other, non-formal types of knowledge" (UNEP/IPBES/2/2 2009, 22). This participatory ambition was also reflected in the actor composition: IPBES started as a multi-stakeholder initiative involving actors as diverse as conservation and indigenous peoples' organizations, prominent scientists involved in global environmental assessments, Multilateral Environmental Agreements and state representatives. IPBES had to position itself in the controversies over the adequate institutional design of expert organizations as well as how a new organization would fit into the already existing structure of science-policy organizations. Proponents in favor of copying the institutional design of the IPCC argued for an intergovernmental organization with a global design, staffed by natural scientists and relying on their expertise (Nature 2010). In contrast, others argued in favor of a multi-stakeholder organization with a more regional orientation that would take into account diverse knowledge systems including that of indigenous and local communities as well as the humanities. Such a multi-stakeholder organization, it was argued, would be better fitted to support the ambition to integrate participation not only in matters of politics but also of science and technology (Turnhout et al. 2012).

Similar to IPBES, Future Earth presents itself as a global, participatory and inclusive knowledge platform. Future Earth was officially launched, also in 2012, at the major academic conference 'Planet under Pressure' (London, March 2012) as well as at the Rio+20 United Nations Conference on Sustainable Development (Rio de Janeiro, June 2012). This dual launch reflects the ambition to play a role in global governance for sustainable development. Future Earth developed on the foundation of several large international research programmes in global environmental change. One of the core principles that distinguishes Future Earth from its predecessors is that of co-production ${ }^{3}$. Co-production of knowledge with societal actors is presented as a new mode of knowledge production essential to addressing the challenges of global sustainability. Co-production, thus, is the way in which Future Earth takes up the imperative of participation. Actors involved in developing the research platform agreed that supporting this ambition called for an innovative institutional design (Future Earth 2013). However, the process of developing a new global research platform involved considerable discussion about what such a platform should look like, which design would best support the objectives of co-production and participation, and who should be involved in what way. In particular, tensions centered around the role of existing research projects versus new initiatives designed to support co-production and participation. Central to the discussion was a search for the appropriate balance between 'curiosity-driven' research and participatory, coproduced and action-oriented knowledge (Leemans 2016; Strohschneider 2016).

3

We use the term co-production as an empirical concept - i.e. as an objective advanced by Future Earth. This interpretation differs from the analytical understanding of co-production developed in STS that examines the constant co-production of science and social order (see Miller and Wyborn 2019). 
Thus, in both cases the ambition of participation forms an important justification for becoming recognized as an epistemic authority. The platforms seek to position themselves as relevant actors in societal transformations toward sustainability and in this endeavor they encounter frictions between their participatory ambitions and conventional ways of producing and assessing authoritative knowledge.

\section{Organizational structure of IPBES and Future Earth}

Organizational structure formed a main point of debate for actors involved in the development of IPBES and Future Earth. In both cases, discussions centered on how extra-scientific actors would participate and whether they would be observers, advisers, or allowed actual decisionmaking power.

In 2010, state and non-state actors decided to design IPBES as a permanent, intergovernmental organization open to all member states of the United Nations (UNEP/IPBES/3/3 2010). ${ }^{4}$ This came with the hope that governments would take IPBES' deliverables into account since they define procedural rules as well as commission and approve official outputs such as biodiversity assessments. While this reasoning resonates with established notions of expert organizations, it only partially reflects IPBES' origin as a multistakeholder initiative that attempts to involve traditionally underrepresented actors such as indigenous peoples and local communities.

Specific elements of IPBES' organizational structure depart from the established path of organizational designs for expert organizations. For instance, IPBES' knowledge-generating body, the MEP, is referred to as an expert body as opposed to a science body. ${ }^{5}$ This shift from "scientist" to "expert" reflects an inclusion of more diverse knowledge systems. Natural sciences should be complemented by the social sciences and humanities; holders of indigenous knowledge should balance the often Western, white, male, "scientific" perspective. To realize this shift, IPBES has introduced rules for the appointment of 25 experts that aims for a balance of representation in region, gender and discipline, and includes indigenous knowledge (IPBES 2012; Kovács and Pataki 2016). However, IPBES has so far not succeeded in fully realizing this balance. Critics have called upon IPBES to "play by [the] rules" it set for itself, and to do a better job in involving "non-elite actors" (Opgenoorth et al 2014). Yet governments barred the creation of an institutional sub-body of IPBES in which stakeholders would oversee their contributions to the organization. Instead, stakeholders are invited to organize themselves in an open-ended network that has no formal role in the institutional architecture of the organization.

Whereas IPBES is set in an intergovernmental context, Future Earth developed in a research landscape with a clear focus on advancing science. in which societal engagement was of secondary importance. In the transition from global change research programmes to Future Earth, a major point of discussion concerned the elaboration of an organizational structure that would support stronger engagement with, and the involvement of, societal stakeholders. Eventually, a dual advisory structure was established consisting of a Science Committee and an Engagement Committee with equal status (Future Earth 2013). The Science Committee brought together internationally respected scientists from a variety of disciplines, whereas the

\footnotetext{
4

A secretariat assists the Plenary as well as IPBES' administrative and expert (MEP) body.

5

The MEP operationalize and integrate governments' requests as well as oversee the selection of expert groups that are tasked to carry out IPBES deliverables.
} 
Engagement Committee consisted of societal stakeholders. A core argument for this dual structure was that it would give extra-scientific stakeholders a strong position in the platform, while also guaranteeing scientific rigor and nimbleness (Leemans 2016). Yet, the advisory structure was also criticized, not least by its own members, for not living up to the participatory ambition of Future Earth. The critique suggested that the dual structure of both a Science Committee and an Engagement Committee effectively separated the 'science' of Future Earth from external influence by limiting the counsel of extra-scientific actors to matters of engagement. After a few years of operation, the two committees were succeeded by a single Advisory Committee. The Advisor Committee comprises of 'high-level representatives of scientific and stakeholder communities,' most of whom hold high-level positions at public and private organizations and have strong scientific track records (Future Earth 2018a) ${ }^{6}$. As such, responsibility for Future Earth's scientific agenda and output remains deeply rooted with experts who have earned their scientific credentials. The main decisionmaking power in Future Earth, however, lies with its Governing Council.

The Governing Council is the main decision-making body of Future Earth and is responsible for setting strategic directions. It was initially envisioned as a multi-stakeholder body "of scientists, policymakers, development actors, representatives of business and industry, civil society and other stakeholders" (Future Earth 2013, 44). However, when Future Earth became operational the role of the Governing Council was taken on by the alliance of international science councils, science funders and UN organizations that had instigated the platform. As such, rather than opening up the platform to external stakeholders, the role of these initiating actors and sponsors was reinforced. However, in 2018, the Governing Council was formally opened up and now formally includes three types of voting members: representatives of 'supporting partners'; representatives of 'international organizations'; and 'strategic leaders' in sustainability transformations (Future Earth 2018b). The platform thus seeks further support of and recognition from key actors in international environmental governance by attracting 'international organizations' and 'strategic leaders' to its governing body. At the same time, the decision-making role of funders of global sustainability research ('supporting partners') remains prominent.

Taken together, we find ongoing struggles over the organizational design of IPBES and Future Earth. The (de)institutionalization of designs reflects the tensions between different perspectives on the participation of stakeholders in knowledge platforms for sustainability. Instead of simply implementing a ready-made model, platforms experiment, muddle through, and call for more participation, while dealing with concerns for recognition by states and the science community.

\section{Conceptual framework of IPBES and Future Earth}

The conceptual frameworks of knowledge platforms reflect how they establish knowledge of phenomena such as biodiversity and sustainability, and what knowledge is considered relevant. For IPBES and Future Earth, the ambition to include different ways of knowing forms a driving force behind the development of and contestations over their conceptual frameworks.

6

Of the thirteen members of the Advisory Committee (November 2018), twelve members have received their doctorate degree. Ten members of the committee, including the two co-chairs, have a professorship and hold or have held leadership positions in academia. 
IPBES' innovative conceptual framework operates as a guiding, "simplified model of the complex interactions between the natural world and human societies" and structures IPBES' current and future work program (Díaz et al. 2015). The process of negotiating this framework revealed a tension between two competing positions on ways of knowing biodiversity. (Borie and Hulme 2015; Hughes and Vadrot 2019). One focuses on the concept of "ecosystem services". This concept has become influential in operationalizing nature or biodiversity as goods and services. For the proponents of this concept, there is nothing suspect about the approach since it links scientific knowledge on biodiversity with policy-making by the identification of goods and the assignment of value to them. The notion of value can be stretched to include non-economic values such as recreational activities. The other position has been most prominently articulated by the Bolivian delegation. Bolivia demanded that the conceptual framework be organized around the notion of Mother Earth (iisd 2013a). This underlines the importance of indigenous knowledge and more broadly, other knowledge systems. Advocates of this position join critics of the ecosystem services approach in suggesting that the very notion of ecosystem services is a manifestation of nature's commodification (Turnhout et al. 2013). They argue against the idea that ecosystem services are a neutral vehicle for engaging with policy-makers and assert, instead, that these services are as deeply political as the notion of Mother Earth.

[Figure two]

Both camps in the negotiations accused the other of arguing politically over knowledgemaking processes. A compromise was developed that allows both framings to be true and is illustrated with a color-coding of the framework. It recognizes "ecosystem services," indicated with green as well as a holistic notion of biodiversity in the concept of "Mother Earth," indicated with blue (Figure two). This demonstrates that the recognition of plural views on nature and biodiversity have become an integral part of the discourse that structures IPBES (Borie and Hulme, 2015). Yet, the recognition of "contrasting rationalities, diverging ontological claims, and different criteria for knowledge validation" remains to be realized (Löfmarck and Lidskog 2017, 28). Two worlds of knowing biodiversity are presented side by side without a vision for integrating them.

An initial conceptual framework for Future Earth was developed during a two-year visioning process, the aim of which was to "explore options and propose implementation steps for a holistic strategy on Earth system research" (ICSU 2010, 2). This strategy and research agenda would have to reflect knowledge and experiences from a diversity of disciplines, including the natural sciences as well as the social sciences and humanities (De Pryck and Wanneau, 2017). One of the main outcomes of the visioning process was the identification of five grand challenges - forecasting, observing, confining, responding and innovating (see Figure three) as the main rationale for the new research platform. These challenges, and those of forecasting and observing in particular, reflect the strengths of earth system science, based in the natural sciences, as developed in the previous decades of global change research. During the visioning process, scholars from the social sciences and humanities in particular suggested that the notion of responding should be prioritized as the main aim of the platform, thereby informing other challenges (Lahsen, 2016). This discussion was, however, not reflected in the final model. The five grand challenges were presented as a core justification for why a large integrated research platform such as Future Earth was needed, thus reinforcing a relatively narrow relevance rationale based on natural science research.

[Figure three] 
Yet, during the subsequent development of Future Earth, the grand challenges framework retreated to the background and was largely replaced by a conceptual framework building on the "fundamental interconnections between natural and human drivers of change" (Future Earth 2013, p. 12). This model of global sustainability research is presented as an innovation that foregrounds the 'social heart' of global environmental change research (Hackmann et al 2014; Castree 2015). It forms the basis of Future Earth's three main research themes: dynamic planet, global development and transformations toward sustainability (Future Earth 2013).

Overall, IPBES' and Future Earth's conceptual frameworks present different perspectives on the knowledge and actors that they represent as well as the objects of knowledge that are created as a result of their design. IPBES' conceptual framework reflects ongoing controversies about the precise definition of terms and their political implications (Hughes and Vadrot 2019). The changes in Future Earth's conceptual framework illustrate relevant developments in the way the platform seeks to position itself and the knowledge it generates as relevant and legitimate in addressing major sustainability challenges.

\section{Participation strategies of IPBES and Future Earth}

Participatory ambitions of knowledge platforms for sustainability are put into practice through the formation of participatory strategies. For both IPBES and Future Earth, the question of who participates and on what grounds was highly debated. Eventually, both platforms developed their own unique institutional strategies for realizing their participatory ambitions.

In 2013, relevant stakeholders were invited to develop, in consultation with IPBES subbodies, a stakeholder engagement strategy (IPBES 2013) out of which arose a first set of controversies concerning issues of representation. The plenary had delegated the facilitation of the process to two major NGOs, the International Council for Science (ICSU) and the International Union for the Conservation of Nature (IUCN). Although most organizations agreed with this process, some indigenous organizations stressed that ICSU and IUCN cannot speak for all stakeholders and underlined the need to "recognize the diversity of [stakeholder] groups collaborating with the Platform" (iisd 2013b). In addition, sub-bodies of IPBES frequently changed the drafts prepared by stakeholders. In one extreme case, the secretariat rewrote the participation strategy, resulting in stakeholder resistance. Those who objected argued that only the strategy developed by the stakeholders themselves would enjoy any legitimation due to the extensive consultative process (IUCN et al 2014).

Throughout the process, the notion of stakeholder remained an essentially contested category. ICSU and IUCN claimed that "stakeholders should be seen as a relationship of partners and not just unspecified generic 'stakeholders' (ICSU and IUCN 2013). Similarly, the indigenous peoples' representative demanded that 'IPBES ... must recognize ...indigenous peoples and local communities, as knowledge-holders, rights-holders, and partners, and recognize our distinct contribution to the platform" (Carino 2013). Notions of rights-holders and partners appeared throughout the drafting process, but IPBES sub-bodies filtered out these categories because a rights-based terminology would grant non-state actors rights within the intergovernmental setting. Most states try to prevent such a situation.

The resulting adopted strategy defines stakeholders as "(a) Contributors: scientists, knowledge holders and practitioners and (b) End users: policymakers" (IPBES 2014, 3). This terminology suggests that stakeholders are invited as knowledge holders with an instrumental, rather than a democratic, vision of stakeholder participation (Garard and Kowarsch 2017). In practice, the notion of stakeholders refers mostly to environmental, conservationist, indigenous peoples and business NGOs as well as Multilateral Environmental Agreements 
that link IPBES to the UN systems. Stakeholder organizations can access the process of knowledge making by nominating up to twenty percent of the experts for the IPBES deliverables with no governing power. They are invited to submit review comments on draft documents as well as participate directly as experts or authors.

Future Earth's main institutional innovation for supporting participation at the research level are so-called Knowledge Actions Networks. They are presented as the main channel for implementing Future Earth's core principles of co-design and co-production through collaborative knowledge development between scientists and societal partners (Future Earth 2016). According to Leemans (2016), many of the global change research initiatives that have transitioned to Future Earth "...were critical on the actual co-design and co-production, a research approach which was often feared as an intrusion on scientific independence" (108). Knowledge Action Networks were meant to signal a departure from the structure of global change research projects, which are based foremost on academic collaboration (Hadley Kershaw 2018). By September 2018, nine Knowledge Action Networks were at different levels of development, addressing topics ranging from urban issues to oceans to health.

Future Earth refers to participants in Knowledge Action Networks as 'experts within and outside of academia' and aims to 'bring together researchers and experts in policy, business, civil society and more' (Future Earth 2016). The role of experts is thus, by design, not reserved for scientific experts alone. The modus operandi of Knowledge Action Networks "is that of generating high quality actionable scientific knowledge through the integration of research and the involvement of societal partners" (Future Earth 2016). Actionable and highquality scientific knowledge is here presented as a shared responsibility and not restricted to scientific expertise. Yet, in the absence of rules and procedures for balancing academic and non-academic leadership and participation, participation often remains restricted to scientific actors by default. Moreover, the primacy of scientific knowledge as both starting point and output of Knowledge Actions Networks limits the interest and potential contribution of nonacademic stakeholders. This might explain why, in contrast to the presented ambitions, the development of Knowledge Action Networks has been slow in practice. While they present a new and innovative structure, it is one that remains disproportionally populated by actors traditionally involved in global change science.

Altogether, the participation strategies of IPBES and Future Earth present a mixed picture. There are indicators that resonate with the metaphor of "opening up" (Stirling 2008). Stakeholders populate the intergovernmental negotiations of IPBES as observers, deliver statements in the Plenary, and even access the process of knowledge making. Similarly, Future Earth's Knowledge Action Networks provide spaces for collaborative knowledge making beyond science. At the same time, we observe an absence of institutional rules that would allow for more formal representation (IPBES), or indeed attract other societal actors (Future Earth).

\section{Conclusion: Dynamics of epistemic authority in knowledge platforms for sustainability}

Our study of IPBES and Future Earth shows that knowledge platforms for sustainability seek epistemic authority by institutionalizing participation at the global level. Our findings reveal how seeking epistemic authority affects institutional design; how design choices shape and enact participation; and how participation, in turn, affects epistemic authority of knowledge platforms for sustainability. Here we discuss our findings and relate them to the literature on epistemic authority in global environmental politics. 
We introduced the conceptualization of knowledge platforms for sustainability in order to examine the trend toward more participatory designs across different types of expert organizations (Garard and Kowarsch 2017; van der Hel 2016; Esguerra et al 2017). Often, scholarship in global environmental politics takes the IPCC or other global environmental assessments as the main reference point for interaction between science and politics. We argue, with others, that a deeper understanding of global environmental politics requires an expansion of empirical focus as well as a new theoretical approach (Gustafsson and Lidskog 2018; Montana 2019). This presents a shift in perspective for the study of epistemic authority in global environmental politics. Instead of assuming that expert organizations enjoy authority by way of delegation, we show how expert organizations strive for recognition and innovate their institutional designs to connect to different audiences.

How does seeking epistemic authority affect institutional design? As novel expert organizations that seek epistemic authority, both IPBES and Future Earth evoke rhetorical strategies of inclusive participation. We observe that actors in the development of both platforms vividly discussed institutional design choices in support of divergent visions of participation. As recent literature on global environmental assessments suggests, participatory ambitions create tension between conventional and novel foundations of epistemic authority (Haas 2017). Our analysis makes visible that the ambitions of participation are only partly supported by developments in institutional design. This tension between the ambition of participation and other modes of supporting epistemic authority (i.e. based on scientific consensus or state-delegation) is reflected in the development of and contestation over different designs. We show how resulting design decisions depend on interactions with various audiences from which knowledge platforms seek recognition (Gustafsson and Lidskog 2018; Sending 2017). Knowledge platforms are strongly embedded in the existing scientific and intergovernmental contexts of world politics and seeking recognition in different contexts calls for different designs IPBES seeks recognition in the intergovernmental context making it more restrictive regarding membership. Future Earth seeks recognition as relevant actor in sustainability transformations and opens up its design to authoritative governance actors in public and private settings. These design choices restrict access for less prominent or privileged stakeholders to shape authoritative knowledge. These findings have implications for research on epistemic communities and GEAs (Mitchell et al 2006; Haas 2017). While most of this literature examines institutional design to account for influence, we show how seeking influence affects institutional design. In other words, prominent categories of the GEA literature such as salience, credibility and legitimacy are by no means neutral; instead, they are the product of complex negotiations over who speaks legitimately about the Earth (Lövbrand et al 2016).

How do design choices shape participation? We utilize a perspective that takes design choices as an inroad into how environmental knowledge is produced, i.e. the contested rules and procedures by which it is made (Beck et al 2017). From this perspective, institutional designs represent power relations in that they determine who can participate in knowledge making and in what ways (Montana 2019). We find that the organizational design of IPBES follows an intergovernmental model that limits room for participation by non-state actors. Future Earth's organizational design departs from a conventional model of scientific autonomy by formalizing the role of stakeholders in its advisory structure and governing body. However, decision-making power is granted mostly to those actors - science councils, funders and UN organizations - with previously established authority in sustainability governance, while the potential for other actors to challenge and shape authoritative knowledge on sustainability remains limited. The conceptual framework of IPBES is where we find institutional innovation (Borie and Hulme 2016; Hughes and Vadrot 2019). It institutionalizes a new way of knowing biodiversity, based on the holistic notion of 'Mother 
Earth,' alongside the more conventional science of ecosystem services. Future Earth's conceptual framework also moves beyond the dominant natural science mode of understanding global change and sustainability, but does not (as with the conceptual model of IPBES) explicitly acknowledge knowledge that challenges conventional scientific understandings. The participatory strategies of IPBES and Future Earth present a mixed picture with some instances of opening up as well as a tendency to limit the participation of elite actors. These findings resonate with STS and IR scholarship on epistemic authority in showing that the practices and designs by which authority is acquired, protected, challenged and expanded have important selective effects (Sending 2015; Beck et al 2017). Overall, both platforms support participation on instrumental grounds (i.e. supporting the legitimacy of the platform and enhancing its impact) rather than by opening up to a diversity of stakeholders in the development of relevant knowledge for biodiversity and sustainability (Beck and Forsyth 2019).

How does the design of participation affect epistemic authority? Design choices affect whose and which knowledge claims are presented as true and relevant by knowledge platforms for sustainability. Innovations in design show that relevant knowledge for biodiversity and sustainability is no longer the exclusive domain of the natural sciences. IPBES opens up alternative understandings of biodiversity through its conceptual model. Future Earth invites extra-scientific actors to shape relevant knowledge for sustainability as part of its participation strategy. As a result, there is a proliferation of ontologies of environmental knowledge. This "opening up" of knowledge platforms for sustainability challenges conventional foundations of epistemic authority. Conventional wisdom holds that knowledge is powerful when it is consensual, that is, when science speaks with one voice (Haas 1992). In contrast, participatory designs are more likely to create competing knowledge claims and not consensual knowledge. This diversified knowledge comes about partly through democratic norms such as contestation and accountability rather than conventional scientific norms (Beck et al 2014; Turnhout et al 2012). In this model, knowledge can become powerful when it is diverse and multiple (Esguerra 2015). However, our findings also point in another direction. The opening up of knowledge platforms is limited by the organizational structures and contexts of both organizations. The dynamics of seeking authority continue to reinforce the dominance of actors already involved in global environmental politics, rather than support less powerful stakeholders to inform or challenge knowledge claims.

In conclusion, the power to shape relevant knowledge on biodiversity and sustainability remains with actors with well-established authority in science and governance for sustainability. Even in knowledge platforms for sustainability, scientific autonomy and consensus remain strong foundations for epistemic authority in the conventional sense. And yet, we find instances of participatory design that challenge the model of autonomous, consensus-based and delegated epistemic authority. We see this tension between conventional and novel foundations of epistemic authority as a defining feature of knowledge platforms for sustainability. In the changing landscape of environmental knowledge making and governance, expert organizations will continue to be under pressure to reinvent their designs in order to become recognized and maintain recognition as authoritative voices in the politics of sustainability.

Alejandro Esguerra is a postdoc at the working group Political Sociology, University Bielefeld, Germany. He obtained his $\mathrm{PhD}$ at the Freie Universität Berlin, researched and taught at Cornell University, UFZ Leipzig, the Centre for Global Cooperation Research Duisburg as well as the University of Potsdam. His work is concerned with the politics of environmental knowledge as well as international political sociology. Among his most recent 
publications are 'Future objects: tracing the socio-material politics of anticipation.' (Sustainability Science 2019) and with Tobias Berger 'World Politics in Translation: Power, Relationality and Difference in Global Cooperation' (Routledge 2018).

Sandra van der Hel is a researcher and junior lecturer at the Copernicus Institute of Sustainable Development, Utrecht University, The Netherlands. Her PhD research focuses on the role of science in governance for sustainability. She is also involved in the Horizon 2020 CreaTures project on creative practices for sustainability transformations. Among her recent publications are 'Science for change: A survey on the normative and political dimensions of global sustainability research' (Global Environmental Change 2018) and 'Research programmes in global change and sustainability research: what does coordination achieve?' (COSUST 2019).

\section{References}

Allan, Bentley B. 2017. Producing the Climate: States, Scientists, and the Constitution of Global Governance Objects. International Organization 71(1): 131-162.

Bäckstrand, Karin. 2003. Civic Science for Sustainability: Reframing the Role of Experts, Policy-Makers and Citizens in Environmental Governance. Global Environmental Politics 3(4): 24-41.

Beck, Silke, Tim Forsyth, Pia Kohler, Myanna Lahsen, and Martin Mahony. 2017. The Making of Global Environmental Science and Politics, in Ulrike Felt, Rayvon Fouche, Clark A. Miller, and Laurel Smith-Doerr, eds., The Handbook of Science and Technology Studies., 1059-1086, Cambridge, MA: MIT Press.

Beck, Silke and Tim Forsyth. 2019. Bridging science and culture: participation and representation of transformative change in biodiversity assessments. In Seeds of Change. Provocations for a New Research Agenda, edited by Wyborn, C., Kalas, N., Rust, N., 54-58. Vienna Austria.

Beck, Silke and Martin Mahony. 2018. The IPCC and the new map of science and politics Wiley Interdisciplinary Reviews: Climate Change 9(6): e547.

Borie, Maud and Mike Hulme. 2015. Framing global biodiversity: IPBES between mother earth and ecosystem services. Environmental Science \& Policy 54: 487-496.

Carino, Joji. 2013. Statement delivered by Joji Carino from the Forest Peoples Programme on behalf of the International Indigenious Forum on Biodiversity and Ecosystem Services at IPBES-2.

Cash, David W et al 2003. Knowledge Systems for Sustainable Development, Proceedings of the National Academy of Sciences of the United States of America 100(14): 8086-91.

Castree, Noel. 2015. Changing the Anthropo(s)cene, Dialogues in Human Geography, 5(3), 301-316.

De Pryck, Kari and Krystel Wanneau. 2017. (Anti)-boundary work in global environmental change research and assessment, Environmental Science \& Policy 77: 203-210. 
Díaz, Sandra et al. 2015. The IPBES Conceptual Framework-connecting nature and people, Current Opinion in Environmental Sustainability 14: 1-16.

Dooley, Kate and Aarti Gupta. 2017. Governing by expertise: the contested politics of (accounting for) land-based mitigation in a new climate agreement, International Environmental Agreements: Politics, Law and Economics 17(4): 483-500.

Esguerra, Alejandro. 2015. Toward two Narratives of Knowledge. Innovation: The European Journal of Social Science Research. 28(1): 3-10.

Esguerra, Alejandro, Silke Beck and Rolf Lidskog. 2017. Stakeholder Engagement in the Making: IPBES Legitimization Politics. Global Environmental Politics 17(1): 59-76.

Future Earth. 2013. Future Earth Initial Design: Report of the Transition Team. International Council for Science (ICSU), Paris, France.

Future Earth. 2016. Knowledge $\rightleftarrows$ Action Networks Framing and Operationalisation. Retrieved

from http://futureearth.org/sites/default/files/framing_and_operationalisation_kans_version_ 1.0.1.pdf

Future Earth. 2018a. Future Earth names inaugural members to its Advisory Committee. Retrieved from http://www.futureearth.org/news/future-earth-names-inauguralmembers-its-advisory-committee

Future Earth. 2018b. Call for application future earth governing council. Retrieved from http://futureearth.org/news/2018-call-application-future-earth-governing-council

Garard, Jennifer and Martin Kowarsch. 2017. Objectives for Stakeholder Engagement in Global Environmental Assessments, Sustainability 9(9): 1571.

Gustafsson, Karin. M., \& Lidskog, R. (2018). Boundary organizations and environmental governance: Performance, institutional design, and conceptual development. Climate Risk Management,19: 1-11.

Haas, Peter M. 1992. Banning chlorofluorocarbons: epistemic community efforts to protect stratospheric ozone. International Organization 46(1): 187-224.

Haas, Peter M. 2017. The epistemic authority of solution-oriented global environmental assessments, Environmental Science \& Policy 77: 221-224.

Haas, Peter M. and Casey Stevens. 2011. Organized Science, Usable Knowledge, and Multilateral Environmental Governance, in Rolf Lidskog and Göran Sundqvist, eds., Governing the Air: The Dynamics of Science, Policy, and Citizen Interaction, 125161, Cambridge, MA.: MIT Press.

Hackmann, Heide, Susanne C Moser and Asuncion Lera St. Clair. 2014. The social heart of global environmental change, Nature Climate Change 4(8): 653-655.

Hadley Kershaw, Eleanor. 2018. Leviathan and the hybrid network: Future Earth, coproduction and the experimental life of a global institution, in Brigitte Nerlich, Sarah Hartley, Sujatha Raman and Alexander Smith, eds., Science and the politics of openness: Here be monsters, 107-130.Manchester, UK: Manchester University Press. 
Hajer, Maarten A., and Peter Pelzer. 2018. "2050-An Energetic Odyssey: Understanding 'Techniques of Futuring' in the transition towards renewable energy", Energy research \& social science 44: 222-231.

Hel, Sandra van. 2016. New science for global sustainability? The institutionalisation of knowledge co-production in Future Earth, Environmental Science \& Policy. (61): 165175.

Hughes, Hannah and Alice Vadrot. 2019. Weighting the World: IPBES and the Struggle over Biocultural Diversity, Global Environmental Politics: (19)2: 14-37.

ICSU. 2010. Earth System Science for Global Sustainability: The Grand Challenges. International Council for Science, Paris.

ICSU and IUCN. 2013. Statements on behalf of ICSU, the International Council for Science, and IUCN, the International Union for Conservation of Nature, on items 7(b).

Iisd. 2013a. Summary of the First Plenary Meeting of the Intergovernmental Platform on Biodiversity and Ecosystem Services. 21-26 January 2013, in Bonn, Germany', Earth Negotiations Bulletin 31(6).

Iisd. 2013b. IPBES-2 Highlights. Wednesday, 11 December 2013. Earth Negotiations Bulletin 31(10).

IPBES. 2012. Functions, operating principles and institutional arrangements of the Intergovernmental Science-Policy Platform on Biodiversity and Ecosystem Services. Adopted by the second session of the plenary meeting to determine the modalities and institutional arrangements for IPBES, held from 16-21 April 2012 in Panama City, Panama.

IPBES. 2013. IPBES/2/13 Communication and stakeholder engagement: Stakeholder engagement strategy. Draft stakeholder engagement strategy for supporting the implementation of the Platform's work programme.

IPBES. 2014. Revised draft stakeholder engagement strategy: deliverable 4 (d). IPBES/3/16.

IUCN, ICSU, and NEFO. 2014. 'Outline of a second version of the IPBES Stakehlder Engagement Strategy. Copy with the authors.

Jasanoff, Sheila. 2005. Judgment under Siege: The Three-Body Problem of Expert Legitimacy. In Sabine Maasen and Peter Weingart Democratization of Expertise? Exploring Novel Forms of Scientific Advice in Political Decision-Making, edited by Sabine Maasen and Peter Weingart, 209-224. Springer: Sociology of the Sciences Yearbook (Vol. 24).

Keller, Ann C. 2010. Credibility and relevance in environmental policy: Measuring strategies and performance among science assessment organizations. Journal of Public Administration Research and Theory 20(2): 357-386.

Krisch, Nico. 2017. Liquid authority in global governance. International Theory 9(2): 237260. 
Kunseler, Eva-Maria and Willemijn Tuinstra. 2017. Navigating the authority paradox: Practising objectivity in environmental expertise, Environmental Science \& Policy 67: $1-7$.

Lahsen, Myanna. 2016. Toward a Sustainable Future Earth: Challenges for a Research Agenda, Science Technology and Human Values 41(5): 876-98.

Littoz-Monnet, Annabelle. 2017. The Politics of Expertise in International Organizations: How International Bureaucracies Produce and Mobilize Knowledge. New York: Routledge.

Leemans, Rik. 2016. The lessons learned from shifting from global-change research programmes to transdisciplinary sustainability science. Current Opinions in Environmental Sustainability 19: 103-110.

Lidskog, Rolf and Göran Sundqvist. 2015. When and how does science matter? International Relations meets Science and Technology Studies. Global Environmental Politics 15(1): $1-20$.

Lidskog, Rolf and Göran Sundqvist. 2018. Environmental Expertise as Group Belonging: Environmental Sociology Meets Science and Technology Studies. Nature and Culture 13(3): 309-331.

Löfmarck, Erik and Rolf Lidskog. 2017. Bumping against the boundary: IPBES and the knowledge divide. Environmental Science \& Policy 69: 22-28.

Miller, Clark A. and Carina Wyborn. 2019. Co-production in global sustainability: Histories and theories, Environmental Science \& Policy.

Mitchell, Ronald Bruce, William C. Clark, David W. Cash, and Nancy M. Dickson. 2006. Global environmental assessments, Cambridge, MA.: MIT Press.

Montana, Jasper. 2019. Co-production in action: perceiving power in the organisational dimensions of a global biodiversity expert process. Sustainability 14:1581-1591.

Nature. 2010. Wanted: an IPCC for biodiversity. Nature 465(7298): 525-525.

Opgenoorth, Lars, Stefan Hotes, and Harold Mooney. 2014. IPBES: Biodiversity panel should play by rules. Nature 506(7487): 159-159.

Sending, Ole Jacob. 2015. The Politics of Expertise: Competing for Authority in Global Governance. University of Michigan Press.

Sending, Ole Jacob. 2017. Recognition and liquid authority. International Theory 9(2): 311328 .

Stirling, Andy. 2008. "Opening up" and "closing down" power, participation, and pluralism in the social appraisal of technology. Science, technology \& human values 33(2): 262 294.

Strohschneider, Peter. 2016. The Conceptualisation of Research in Global Sustainability, Foreword in Schmalzbauer, Bettina and Martin Visbeck (Eds.) 2016. The contribution of science in implementing the Sustainable Development Goals. German Committee Future Earth, Stuttgart/Kiel. 
Turnhout, Esther, Bob Bloomfield, Mike Hulme, Johannes Vogel, and Brian Wynne. 2012. Conservation policy: Listen to the voices of experience, Nature 488(7412): 454-455.

Turnhout, Esther, C. Waterton, K. Neves, and M. Buizer. 2013. Rethinking biodiversity: from goods and services to "living with", Conservation Letters 6(3): 154-161.

UNEP/IPBES/2/2. 2009. Executive Summary: Science-policy interface on biodiversity and ecosystem services - gap analysis, Nairobi: UNEP available at http://www.ipbes.net/component/content/article/24-ipbes/ipbes-meetings/previousmeetings/184-3rd-meeting-on-ipbesold-version.html (accessed 20 March, 2014).

UNEP/IPBES/3/3. 2010. Report of the third ad hoc intergovernmental and multi-stakeholder meeting on an intergovernmental science-policy platform on biodiversity and ecosystem services., Busan: UNEP available at http://www.ipbes.net/previous-ipbesmeetings/3rd-meeting-on-ipbes.html (accessed 20 March, 2014).

Zürn, Michael, Martin Binder, and Matthias Ecker-Ehrhardt. 2012. International authority and its politicization. International Theory 4(01): 69-106. 